\title{
A IMPORTÂNCIA DA GESTÃO DE PESSOAS PARA O SUCESSO ORGANIZACIONAL
}

\author{
Felipe Tavares Ribeiro ${ }^{1}$ \\ Suelen Moreira ${ }^{2}$ \\ Rafael Gonzalez Bastos ${ }^{3}$ \\ Leonel Godinho da Silva Junior ${ }^{4}$ \\ Cristiano Ollé Pereira ${ }^{5}$ \\ Cesar Moraes de Souza ${ }^{6}$
}

RESUMO: A valorização do capital humano tem sido uma das principais preocupações das organizações, pois se sabe que em um mercado cada vez mais competitivo e com tanta tecnologia disponível o diferencial de uma empresa está no comportamento e comprometimento das pessoas envolvidas. Deste modo, o presente trabalho é um estudo que tem por finalidade identificar os fatores que influenciam o clima organizacional das empresas. Foram levantados referenciais teóricos sobre assuntos acerca do tema. Pretendese, através deste estudo, contribuir para uma maior transparência do papel da gestão de recursos humanos como fonte de estratégia empresarial.

Palavras-chave: Valorização. Organizações. Competitivo.

INTRODUÇÃO

A valorização do capital humano tem sido uma das principais preocupações das organizações, pois se sabe que em um mercado cada vez mais competitivo e com tanta tecnologia disponível o diferencial de uma empresa está no comportamento e comprometimento das pessoas envolvidas. As empresas estão confirmando a precisão da formação de grupos motivados, que se identifiquem com o que realizam e que estejam felizes em seu ambiente de trabalho.

O Clima Organizacional é um instrumento que reflete a real dinâmica deste ambiente, procurando chances de aprimoramento que consigam ser efetivadas pelo setor de Recursos Humanos, através de crenças e valores cria-se a Cultura Organizacional de uma empresa, através dela a administração decide suas intervenções frente a uma dificuldade,

${ }^{\mathrm{I}}$ Graduado em Direito pela Faculdade Anhanguera.E-mail: feliperibeirobm@hotmail.com

${ }^{2}$ Graduada em Educação Física. - Escola Superior de Educação Física pela Universidade Federal de Pelotas

${ }^{3}$ Engenheiro Civil Empresarial pela Universidade Federal do Rio Grande do Sul

${ }^{4}$ Tecnologia em sistemas para internet. Instituto Federal do Rio Grande do Sul

${ }^{5}$ Graduado em Educação Física pela Universidade Federal de Rio Grande -FURG - Rio Grande do Sul

${ }^{6}$ Graduado de Engenharia Mecânica Universidade Federal de Rio Grande - FURG - Rio Grande do Sul 
seja ela interna ou externa.

Por essa razão, a Gestão de Recursos Humanos sofre influência da Cultura Organizacional, pois ela contribuiu para a definição acerca de punições e recompensas dadas aos colaboradores, define o tipo de ambiente adequado para a execução das tarefas da empresa e os comportamentos que precisam ser incitados ou evitados pelos funcionários. Por isso, é essencial que os administradores e colaboradores conheçam a Cultura Organizacional da empresa, a fim de que consigam exercer suas funções da melhor forma possível.

Uma empresa de sucesso possui um setor de gestão de pessoas muito bom, visto que, é ele que faz o recrutamento, o desenvolvimento e a avaliação dos colaboradores da mesma. Por intermédio das metodologias da gestão de pessoas é possível visualizar a direção que a empresa necessita seguir. A grande inquietação de algumas organizações encontra-se no capital financeiro, e por meio do presente trabalho será viável a percepção do capital humano, uma vez que, trata-se do principalativo empresarial, além de ser o menos custoso de gerir e investir.

Por este motivo, o presente artigo procura responder ao seguinte questionamento: qual a importância da gestão de pessoas para o sucesso da organização?

O método de coleta de dados utilizado neste artigo deu-se através de uma abordagem qualitativa. Na concepção de Michel (2009), na pesquisa qualitativa a verdade não se comprova numérica ou estatisticamente, porém convence na forma De experimentação empírica, a partir da análise feita detalhadamente, abrangente, consistente e coerentemente, assim como na argumentação lógica das ideias.

Para a construção do artigo aqui apresentado, foram utilizadas fontes bibliográficas, que culminaram em uma pesquisa de cunho descritivo exploratório.

O trabalho de conclusão de curso estrutura-se em quatro seções, apresentando-se na primeira os processos compreendidos na administração. Na segunda seção é abordado a respeito da gestão de pessoas e suas transformações ao longo dos anos. A terceira seção retrata sobre a gestão de $\mathrm{RH}$ na atualidade, seguida da seção sobre cultura e clima organizacional. 


\section{ADMINISTRAÇÃO}

Os processos de trabalho desenvolvidos nas organizações, instituições ou empresas, transformam objetos por intermédio de instrumentos e meios, procurando alcançar os objetivos. Antigamente, as empresas eram pequenas e de fácil controle. Contudo, cresceram devido ao constante avanço da sociedade e atingiu uma dimensão que foi criada uma disciplina para pensar, discutir e viabilizar a sua estruturação (GRECO, 2012). As empresas necessitam da Administração de seus recursos e pessoas, para trabalharem em conjunto, por meio do planejamento, de objetivos, da condução dos recursos e da estruturação do processo produtivo e das atividades. A administração é uma área de relevância na condução de um negócio. Porque sem que haja uma administração eficiente, fica praticamente impossível das empresasse manterem no mercado. É por meio da administração que as empresas são conduzidas. Sendo assim, administração é o ato de trabalhar com e por meio de pessoas para realizar os objetivos tanto das empresas quanto de seus membros (MONTANA, CHARNOV, 2003). O administrador que age estrategicamente tem uma mentalidade diferenciada dos demais empreendedores, denominada, consciência estratégica ou o pensamento sistêmico, que segundo Andrade, et al (2005) engloba fatores não só relacionados às atividades e processos, mas também humanos, de mercado, financeiros, tecnológicos, estruturais, entre vários outros.

De acordo com os autores, o pensamento sistêmico é a capacidade de perceber, modelar e avaliar as consequências das ações de maneira expandida no tempo e espaço é uma forma de pensar e construir conhecimento, no sentido cognitivo, em que o processamento deste conhecimento é influenciado por uma linguagem de base sistêmica.

$\mathrm{O}$ processo de administração para os autores visa efetuar um planejamento estratégico de suas ações, controlando as atividades necessárias, organizando as tarefas de modo que essas sejam realizadas com eficácia e direcionando todo o contexto do processo por meio da motivação dos profissionais que irão realizar as atividades propostas, buscando atender as metas e objetivos iniciais.

Os administradores realizam tarefas identificadas para atingir os objetivos traçados pela empresa, o processo de administração, considerando Peci e Sobral, (2008) está 
demonstrado na Figura I:

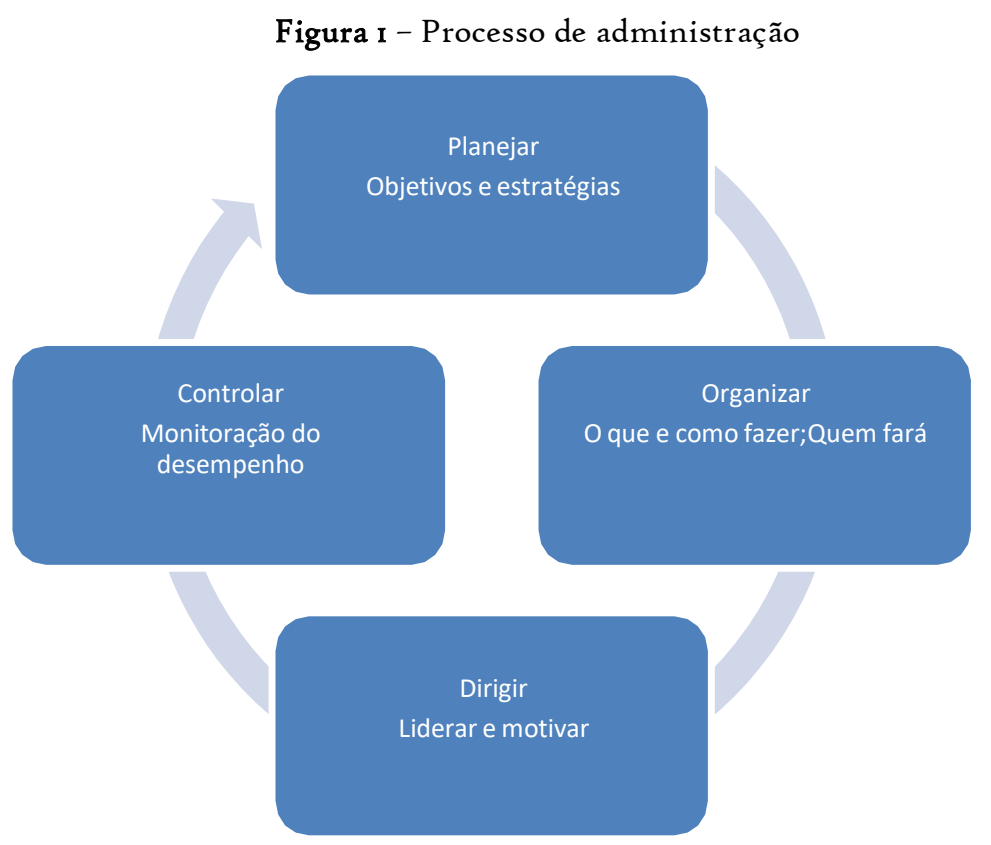

Fonte: Adaptado de Peci e Sobral (2008, p. 8).

Toda empresa precisa ser dirigida, e para que seus objetivos possam ser alcançados se faz necessário o uso de ferramentas da Administração. Quanto aos administradores, na opinião de Silva (2008, p. 12) "são pessoas importantes em qualquer empresa ou entidade. São encarregados de fazer planos, organizar, dirigir e controlar as operações, por meio do esforço conjunto de empregados”. Concordando com o autor, Maximiano (200o) exclama que administrar é um processo de aplicação de recursos visando o alcance dos objetivos, os quais são obtidos por meio das seguintes etapas:

- Planejar é definir objetivos, atividades e recursos;

- Organizar é definir responsabilidades para a execução do que foi planejado

- dirigir é mobilizar e acionar os recursos para a realização das atividadesque conduzirão aos objetivos;

- Controlar é o processo de assegurar a realização dos objetivos e de identificar a necessidade de modificá-los;

As funções organizacionais são as tarefas executadas por pessoas e grupos, para que as organizações alcancem seus objetivos.

As organizações dividem-se em áreas funcionais, as quais representam atividades 
especializadas que são executadas por departamentos ou unidades organizacionais, pode haver diversas áreas em uma empresa, dependendo de sua atividade principal e seus objetivos, segundo Sobral e Peci (2013), as principais áreas da administração são:

Produção: Refere-se à fabricação que comporta o processo produtivo da empresa, a programação controle dos produtos produzidos e a Qualidade dos produtos produzidos, bem como, as prevenções de erros no processo produtivo e ascorreções necessárias para que os processos sejam executados com eficiência

Marketing: Responsável pela Promoção: material promocional, promoção, publicidade, propaganda e amostra grátis. Mas também trabalha a questão dos Preços: estudos e análises e estrutura de preços, bem como, descontos e prazos

\section{Finanças:}

- Planejamento de recursos financeiros: orçamentos; programação das necessidades de recursos financeiros; projeções financeiras; análise do mercado de capitais.

- Captação de recursos financeiros: títulos, empréstimos e financiamentos, administração de contratos.

-Gestão dos recursos disponíveis: pagamentos, recebimentos, operações bancárias, fluxo de caixa, acompanhamento do orçamento financeiro.

- Seguros: análise do mercado securitário, contratação de apólices, administração de apólices, liquidação de sinistros.

\section{Recursos Humanos:}

- Planejamento: programação de necessidades de pessoal, análise de mercado de trabalho, pesquisa de recursos humanos, orçamento de pessoal.

- Suprimento do quadro: cadastramento de candidatos a emprego, recrutamento, seleção, registro e cadastramento, contratação de mão-de-obra de terceiros.

- Gestão de recursos humanos: movimentação de pessoal, cargos e salários, controle de pessoal, acompanhamento de orçamento de pessoal, relações com sindicatos.

- Desenvolvimento de recursos humanos: avaliação de desempenho, acompanhamento de pessoal, treinamento.

- Pagamentos e recolhimentos: folha de pagamento, encargos sociais, rescisões de contratos de trabalho - auxílios. 


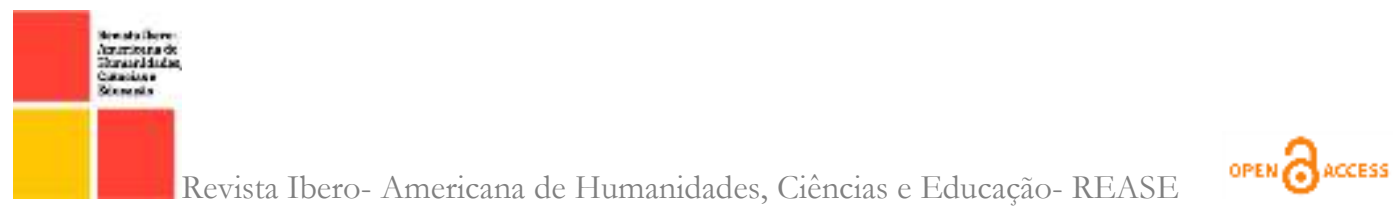

- Benefícios: assistência médica, empréstimos e financiamentos, lazer, assistência social.

\section{I Gestão de pessoas}

A área de gestão de pessoas vem sofrendo mudanças frequentes com o passar do tempo. As empresas precisam estar alinhadas estrategicamente para que se possa acompanhar as mudanças e obter êxito na administração de pessoal. A forma de gerirpessoas como simples recursos das organizações perdeu espaço, e hoje é necessário considerar as pessoas como pessoas.

Segundo Sobral e Peci (2013), as principais áreas da administração são:a gestão de pessoas é uma responsabilidadedistribuída em toda a estrutura da organização. Mesmo que exista a área de Recursos Humanos (RH), a gestão de pessoas não é um dever exclusivamente da área, e sim de todos os gestores, e a área de $\mathrm{RH}$ ficará responsável pela formulação de políticasque alinhem as práticas de gestão de pessoas feitas pelos gestores e áreas da organização diariamente. Sendo assim, é fundamental que os gestores saibam a filosofia e cultura da empresa, para que possam gerir as pessoas da melhor maneira possível, buscando sempre incentivar e consequentemente estimular as capacidades e habilidades do colaborador.

Para Ribeiro (2012, p. or), lidar com pessoas nas organizações atualmente é uma tarefa mais complexa em relação há poucos anos. A área de recursos humanos tem o objetivo de administrar a relação entre organização e pessoas, que são consideradas hoje, parceiras do negócio e não apenas recursos empresariais.

Ribeiro (2012) ainda diz que, a área de gestão de pessoas é uma das que mais têm sofrido mudanças e transformações nos últimos anos. Com a globalização dos negócios, o desenvolvimento tecnológico, o forte impacto da mudança e o intenso movimento por qualidade e produtividade surgiram as constatações nas organizações.

de que o grande diferencial, a principal vantagem competitiva das empresas decorre das pessoas que geram e fortalecem a inovação. Portanto, apesar dos grandes avanços tecnológicos, as pessoas continuam sendo parte importante nas empresas, e sendo conduzidas de maneira correta, podem desenvolver todo seu potencial, trazendo vantagens e sendo o grande diferencial da organização (RIBEIRO, 20I2, p.o2). 
Vergara afirma que gestão de pessoas é um tema de grande importância, pois as pessoas passam a maior parte da vida no interior das empresas, e porque as organizações podem ser tudo, mas nada serão se não houver pessoas que definama visão, as estruturas e estratégias, que estabeleçam metas, e que administrem todos os procedimentos existentes dentro da organização. Ainda diz que “...empresas não nascem da terra, no céu ou no mar. Elas são construções sociais." (VERGARA, 2009, p. 09).

A prática de gestão de pessoas nas empresas é fundamental para a motivação e satisfação dos colaboradores, pois é através destas práticas que a empresa irá captar as características, habilidades e necessidades do funcionário. Práticas como oprocesso seletivo, capacitação profissional, avaliação de desempenho, remuneraçãoe plano de carreira, entre outras, são fundamentais para que o indivíduo possa desempenhar seu potencial, se sinta bem no ambiente de trabalho e tenha uma boa qualidade de vida.

Percebe-se que a remuneração é um dos principais fatores que influenciam a satisfação dos colaboradores. Em relação a este aspecto Limongi-França (2014, p. 66) nos diz que "A gestão da remuneração se constitui, assim, numa das tarefas mais importantes e complexas da gestão de pessoas.”. Segundo Moreno (2014, p. 222), “Adefinição de plano de carreira, de acordo com a expectativa que a empresa e seus funcionários mantêm diante do mercado, é um vantajoso ganho nas modernasorganizações”, e ainda diz que, um plano de carreira aliado a diferentes modalidades de remuneração e a pacotes de benefícios são investimentos realizados para a retenção dos melhores funcionários.

Moreno (2014) mostra a importância da implementação de plano de cargos e salários e diz que "A temática de cargos e salários torna-se cada vez mais comum entre as organizações e seus colaboradores.”, e ainda afirma que para que para ter uma equipe engajada e alinhada às exigências do mercado o plano de cargos e salários deve ser implementado com os objetivos de estabelecer padrões salariais em

todos os níveis da organização, reconhecer e premiar funcionários que agregam valor ao trabalho final por meio do seu desempenho, atrair e reter profissionais cujo desempenho contribua para os resultados da empresa, monitorar constantemente osimpactos da folha de pagamento, adotando parâmetros de controle e redução salarial e ainda desenvolver mecanismos que garantam a competitividade dos salários, em relação ao mercado (MORENO, 2014, p. 223-224). 
E para finalizar, Moreno (2014, p. 230), ainda diz sobre o plano de cargos e salários que "Maximizar o desempenho da empresa e do colaborador, alinhando objetivos comuns entre eles, e garantir o equilíbrio salarial interno e o externo são perspectivas geradas no decorrer das fases de implementação do plano de cargos e salários.”. Por isso, acredita-se que um plano de cargos e salários é muito importante para definição de parâmetros de remuneração justos dentro da empresa, trazendo benefícios para todos.

Outra ferramenta muito útil e eficaz nas empresas é a avaliação de desempenho. Segundo Limongi-França, "A avaliação de desempenho, dentro das empresas, tem como meta diagnosticar e analisar o desempenho individual e grupal dos funcionários, promovendo o crescimento pessoal e profissional, bem como melhor desempenho.”. Ainda segundo a autora, quando a avaliação é feita positivamente trazmuitos benefícios a todos, e a grande vantagem de ter uma política de avaliação de desempenho, é permitir que o próprio desempenho melhore, ou seja, "Essa é a principal razão da avaliação: o retorno sobre a qualidade melhora o desempenho." (LIMONGI-FRANÇA, 20I4, p.Ir6).

Limongi-França ainda afirma que

A avaliação de desempenho fornece à Administração de Recursos Humanos informações importantes, sobre as quais serão tomadas decisões administrativas, tais como nível de salário e bonificação, promoções e demissões, necessidades de treinamento, planejamento de carreira. Toda avaliação de desempenho possui seu retorno, que consiste na divulgação das informações para o funcionário. Os resultados da avaliação de desempenho certamente têm papel determinante na motivação dos funcionários. O objetivo da avaliação de desempenho é também proporcionar o crescimento e desenvolvimento da pessoa que fica sabendo como está se saindo notrabalho. (LIMONGI-FRANÇA, 2014, p. II7).

Através da afirmação da autora, pode-se perceber que a avaliação de desempenho é uma ferramenta que traz muitas possibilidades à administração, sendo

fundamental na tomada de decisões e criação de outros processos na área de recursos humanos, além de trazer benefícios a própria pessoa avaliada.

Entende-se que é impossível existir organização sem as pessoas, e para que possam desempenhar um bom trabalho, a área de recursos humanos é fundamental,pois se a gestão de pessoas for da maneira correta, é provável que se tenham resultados positivos, tanto para a empresa como para o trabalhador. Neste sentido, entende-se que é fundamental que se tenha atenção e se desenvolva um bom trabalho sobre todos os aspectos em relação à satisfação e motivação dos funcionários. 


\title{
2.2 CULTURA E CLIMA ORGANIZACIONAL
}

\subsection{Cultura}

A definição de cultura é procedente da Antropologia. Edward Taylor (1832- 1917) foi o pioneiro no emprego da expressão cultura e, para ele, o citado conceito abrange crenças, conhecimento, leis, arte moral, costumes e demais hábitos ou capacidades contraídos pelo ser humano como componente da sociedade.

De acordo com Russo (2010) a expressão Cultura Organizacional foi instituída no séc. XVIII como uma forma sintetizada para gestão do comportamento e pensamento do ser humano. Somente um século depois que tal expressão veio a serefetivamente utilizado. Schein mencionado por Russo (2010, p. 18) exibe a seguinte definição de cultura organizacional:

\begin{abstract}
Cultura Organizacional é um padrão de pressupostos básicos compartilhados que um grupo aprendeu ao resolver seus problemas de adaptação externa eintegração interna e que funcionou bem o suficiente para ser considerado válido e ensinado a novos membros como a forma correta de perceber, pensar e sentir com relação a esses problemas (RUSSO 2010, p. 18).
\end{abstract}

Segundo Chiavenato (2020, p. 434) "Cultura Organizacional pode ser compreendida como uma forma de vida, um código de valores, crenças e expectativas, uma maneira de intercâmbio e relação peculiar de certo empreendimento".

No meio empresarial, cultura organizacional faz referência a um modo de perceber corriqueiro, dividido pelos componentes de um empreendimento, um código de crenças, valores, normas e rituais seguidos por uma instituição.

A cultura organizacional é entendida também como um conjunto de valores compartilhados entre os membros da organização." (...) "Podendo ser definida, portanto, como um sistema bem desenvolvido e profundamente enraizado de valores que estimula, quando adequadamente gerenciado, membros da organização a produzirem mais, e ter mais criatividade, e consequentemente melhor desempenho organizacional." (RUSSO 2010, p. I8 e I9).

\subsubsection{Clima Organizacional}

O conjunto de atitudes, valores e padrões de comportamento, informais ou formais, que existem em uma organização é chamado Clima organizacional. Trata-se de um montante de valores ou atitudes que atingem o modo como os indivíduos interagem uns com os outros e com o próprio negócio. Assim, compreende-se que o citado clima é, igualmente, a característica da atmosfera de trabalho, consistindo a referida característica 
de boa ou má qualidade, causando grande influência em sua postura. A empresa não cunha seu clima organizacional, tendo em vista que em meio a um mesmo negócio é possível encontrar climas distintos em uma mesma circunstância, com resultados dessemelhantes em consonância com os episódios provocando percepções negativas para uns e positivas para outros. "O clima organizacional diz respeito a atmosfera interior que há em meio aos componentes da empresa e este encontra-se densamente conexo ao nível de incentivo dado aos seus integrantes." (CHIAVENATO 2002, p.95).

A expressão clima organizacional faz uma alusão específica às condições motivadoras encontradas na atmosfera organizacional, em outras palavras, as características da empresa que induzem ao acendimento de distintas formas de incentivo naqueles que nela atuam. Deste modo, o clima organizacional é apropriado no momento que causa contentamento as necessidades individuais dos integrantes eascensão do moral. É avessa no momento que gera frustração dessas necessidades. $\mathrm{Na}$ realidade, o clima organizacional causa influência no estado de motivação dos indivíduos e é pelo referido influenciado.

Em consonância com Kanaane (1999) no momento que se alcança a criação de um clima organizacional que causa o contentamento das necessidades de seus integrantes, originando incentivo para o cumprimento das finalidades da empresa, obter-se-á um ambiente adequado para a elevação da eficiência dessa empresa. Em colocações mais simples (Chiavenato 2020) assegura que o clima dependerá da

maneira que a direção vai empregá-lo com os valores e políticas que existem, da composição organizacional, das competências de cada empregado da organização, da natureza de negócio e da fase de vida da organização. Juntando tudo e auxiliando a criar o clima em cada empreendimento.

O clima é constituído pelas emoções que os indivíduos compartilham sobre a empresa e que afetam de positiva ou negativamente sua alegria e motivação para o trabalho. Sentimentos negativos geram impactos negativos acerca do desempenho, derivando em um clima onde preponderam sentimentos como tensão, receio, inquietação e desgosto, além de inimizade, desesperança e agressividade. Sentimentos positivos desempenham resultados também positivos. A concretização de um desígnio coletivo gera 
um clima no qual preponderam sentimentos como contentamento e vontade de continuar no grupo.

\section{CONSIDERAÇÕES FINAIS}

A importância da Gestão estratégica dos Recursos Humanos de uma empresa, portanto, é inegável e crescente. É através desta gestão que a empresa poderá desenvolver habilidades e qualidade de produção e produtividade suficientes para melhor se posicionar em um mercado globalizado e competitivo da atualidade.

Através dela a empresa poderá criar oportunidades para seu crescimento, novos caminhos de sucesso e contribuir para a melhor qualidade devida de seus funcionários.

Planejar é imperativo em um mundo concorrido e globalizado como hoje. Planejar estrategicamente é essencial, com uma visão em médio prazo e definição de ações estratégicas e metas a serem alcançadas. Realizar tal planejamento estratégico na área de recursos humanos de uma empresa é promover a valorização dos empregados e o crescimento da qualidade de seus serviços e produtos.

O clima organizacional de uma empresa está diretamente ligado aos aspectos positivos e negativos do ambiente de trabalho. Conhecer quais são estes aspectos é indispensável para que se consiga manter um clima saudável e satisfatório na organização, e isso é possível se os colaboradores tiverem a oportunidade de ser manifestar e mostrar a sua percepção perante a estes aspectos. A pesquisa de clima organizacional é um instrumento de suma importância e pode ser um aliado nas organizações na busca de fatores que estejam prejudicando e tornando o ambiente de trabalho desfavorável.

Para atingir o objetivo proposto, utilizou-se como base para a realização deste estudo, referenciais teóricos que foram levantados sobre assuntos que englobam o tema da pesquisa. Através desta base teórica se pode perceber a necessidade de haver uma boa administração da área de gestão de pessoas nas empresas. As teorias pesquisadas mostraram também a importância da realização periódica da pesquisa de clima organizacional, onde ficou explícito que é uma ferramenta adequada e eficazpara que as empresas mantenham seus colaboradores satisfeitos e motivados,trazendo benefícios para todos.

Por fim, o presente artigo pretendeu contribuir de forma significativa para os próximos estudos a respeito do tema, favorecendo a análise de inúmeros autores a respeito 
do tema e a consolidação da importância dos recursos humanos no mundo empresarial atual. Este trabalho mostra a importância inestimável de as organizaçõesinvestirem no seu capital humano, pois as teorias nos mostram que colaboradores

satisfeitos e motivados são mais competentes e eficazes no ambiente de trabalho,sendo o grande diferencial de uma empresa.

\section{REFERÊNCIAS}

ANDRADE, N. A. et al. Planejamento governamental para municípios: plano plurianual, lei de diretrizes orçamentárias e lei orçamentária anual. São Paulo: Atlas, 2005.

BITENCOURT, Claudia Cristina (Coord.). Gestão contemporânea de pessoas: novas práticas, conceitos tradicionais. 2. ed. Porto Alegre: Bookman, 2010.

CHIAVENATO, Idalberto. Gerenciando pessoas: como transformar os gerentes em gestores de pessoas. $4^{\mathrm{a}}$ ed. São Paulo: Prentice Hall, 2002.

Paulo: Atlas, 2020.

. Recursos Humanos: o capital humano das organizações. II ${ }^{\underline{a}}$ ed. São

GRECO, Rogério. Curso de direito penal: parte geral. i4.ed. Rio de Janeiro:Impetus, 2012.

LIMONGI-FRANÇA, Ana Cristina. Práticas de recursos humanos - PRH: conceitos, ferramentas e procedimentos. São Paulo: Atlas, 2014.

KANAANE, Roberto. Comportamento humano nas organizações: o homem rumo ao século XXI. 2. ed. São Paulo: Atlas, 1999.

MAXIMIANO, Antonio Cesar Amaru. Introdução à administração. 5 ed. São Paulo: Atlas, 2000.

MICHEL, Maria Helena. Metodologia e pesquisa científica em ciências sociais. 2.ed. São Paulo: Atlas, 2009.

MONTANA, Patrick J; CHARNOV, Bruce H. (Tradução Robert Brian Taylor; revisão técnica Reinaldo O. da Silva). Administração. São Paulo: Saraiva, 2003.

MORENO, Amanda Izabelle. Administração de cargos e salários [livro eletrônico].

I. Ed. Curitiba: InterSaberes, 2014. PDF. Disponível em: http://upf.bv3.digitalpages.com.br/users/publications/9788582129937. Acesso em: 12jul. 2021.

SOBRAL, Filipe; PECI, Alketa. Administração: teoria e prática no contexto brasileiro.

São Paulo: Pearson Prentice Hall, 2013. 
RIBEIRO, Antonio de Lima. Gestão de pessoas. $2^{-a}$ ed. São Paulo: Saraiva, 2012.

RUSSO, G. M. Diagnóstico da cultura organizacional: o impacto dos valores organizacionais no desempenho das terceirizações. Rio de Janeiro: Elsevier, 2010.

SILVA, Danielly Magalhães da; NUNES, Leandro de Azevedo; ARAGÃO, Nelma Araujo; JUCHEM, Dionise Magna. A importância do Relacionamento Interpessoal no contexto Organizacional. 2008.

VERGARA, S. C. Projetos e relatórios de pesquisa em administração. II $^{\underline{a}}$ ed. São Paulo: Atlas, 2009. 